\title{
Prevention measures against COVID-19 performed by people with diabetes mellitus
}

\author{
Sherida Karanini Paz de Oliveira*1, Amelina de Brito Belchior ${ }^{1}$, Rhanna Emanuela Fontenele de Lima Carvalho ${ }^{1}$, \\ Natércia Brígido Linhares Fernandes ${ }^{1}$, Rebeca Furtado Fernandes ${ }^{1}$, Natasha Vasconcelos Albuquerque ${ }^{2}$, Patrícia Freire \\ de Vasconcelos ${ }^{3}$ \\ ${ }^{1}$ Universidade Estadual do Ceará, Brazil \\ ${ }^{2}$ Universidade Federal do Ceará, Brazil \\ ${ }^{3}$ Universidade da Integração Internacional da Lusofonia Afro-Brasileira, Brazil
}

Received: October 9, 2020

DOI: $10.5430 /$ jnep.v11n3p47
Accepted: November 15, $2020 \quad$ Online Published: November 22, 2020

URL: https://doi.org/10.5430/jnep.v11n3p47

\begin{abstract}
In the absence of treatment and vaccine against coronavirus, preventive measures must be adopted, especially by people with diabetes. The objective was to identify the preventive measures against the new coronavirus carried out by people with diabetes. This is a cross-sectional study carried out with 214 people with diabetes through a questionnaire provided by a Google forms link in June 2020. We used descriptive statistics and the Spearman test to compare means. Most participants were female (85.9\%), young adults $(84.1 \%)$, with type 1 diabetes $(76.7 \%)$, and without complications (74.2\%). A high average of glycated hemoglobin $(7.5 \pm 1.4)$, changes in selfcare routine $(72 \%)$ and in blood glucose levels $(72.8 \%)$, wearing masks $(98.1 \%)$, washing hands with soap and water $(96.7 \%)$, using alcohol gel (94.4\%), and social distancing (85\%) were observed. It is essential to reinforce care for the metabolic control of people with diabetes, in addition to optimizing strategies against the COVID-19 epidemic with a view to preventing and promoting health.
\end{abstract}

Key Words: Diabetes mellitus, Coronavirus infections, Disease prevention, Prevention and control

\section{INTRODUCTION}

The pandemic caused by the new coronavirus called SARSCoV-2 (and the disease called COVID-19) is an international public health emergency with capacity for geometric dissemination, great global socioeconomic impact, and high mortality rates. ${ }^{[1,2]}$

Until September 10, 2020, Brazil recorded the third-largest number of confirmed cases of COVID-19 (4.2 million) in the world, with a mortality rate of 605/million inhabitants, totaling 128,857 confirmed deaths, with 67,691 tests per million inhabitants. ${ }^{[3]}$
There is a great concern about a disease that has spread rapidly in various regions of the world, with different impacts $^{[2]}$ that are causing global mourning and a growing feeling of insecurity and uncertainty, especially for those living with a chronic condition, ${ }^{[4]}$ such as diabetes.

Diabetes mellitus (DM) has emerged as one of the most serious health problems in the world. ${ }^{[5]}$ Brazil has the largest number of people with diabetes in Latin America, reaching 16.5 million $^{[6]}$ and is among the countries with the highest number of confirmed cases and deaths caused by COVID$19 .^{[7]}$

*Correspondence: Sherida Karanini Paz de Oliveira; Email: karanini@ yahoo.com.br; Address: Universidade Estadual do Ceará, Brazil. 
Diabetes can worsen the severity of infections, ${ }^{[8]}$ showing a relationship with greater weight loss and greater lung inflammation, with macrophage infiltrates, ${ }^{[8]}$ especially in a new virus and disease.

When compared to the general population, people with diabetes have a similar risk of contracting COVID-19. However, once infected, they are more vulnerable to the most severe form of the disease $\mathrm{e}^{[9,10]}$ due to a state of metabolic inflammation, predisposing to an increased release of cytokines. In addition, diabetes is associated with several macrovascular and microvascular complications that affects the patient's overall survival. ${ }^{[9]}$

Prevention and control strategies against the spread of the new coronavirus, including traditional public health activities, are still the main priorities for reducing the number of cases and controlling the pandemic. ${ }^{[11,12]}$

Thus, there is an urgent need for further studies to fill the gaps and find strategies to prevent and/or decrease the spread, sensitize people to prevention, and to optimize care for patients with COVID-19, especially those who are in the groups at risk, like people with diabetes. Therefore, we use the following question: what preventive measures are being taken by people with diabetes?

Considering that diabetes is an important risk factor for adverse results of COVID-19, identifying the preventive measures adopted by people with diabetes can favor the identification of gaps and the development of interventions aimed at specific and individual needs of this public, with a view to promoting health and preventing infections and complications. Thus, the objective of the study was to identify the preventive measures against the new coronavirus carried out by people with diabetes.

\section{METHOD}

This is a cross-sectional study conducted with 214 people with diabetes. A form with closed questions was shared once a week in specific groups about diabetes available on social media tools, such as WhatsApp and Facebook, through a direct link to Google Forms in June 2020. Therefore, the nature of the study sample was for convenience.

Social networks are perfect environments for studying various themes and have become important fields for collecting research data with voluntary collaboration of people. ${ }^{[13]}$

The inclusion criteria were being over 18 years old, diagnosed with diabetes for at least six months; having access to the internet to answer the questionnaires through a link, and accepting the terms to share anonymous and non-traceable answers.
The data collection form was created by the authors and consisted of two parts. The first part contains socio-demographic data related to age, gender, state of residence, educational level, income, work activity, and clinical data about the type of diabetes, glycated hemoglobin values, presence or absence of comorbidities, and/or complications. The second part was characterized by questions related to the pandemic including protection measures against COVID-19, type of mask used by the participants, changes in the selfcare routine and changes in blood glucose values.

The collected data were organized in a Microsoft Excel spreadsheet, through double typing and validation to control possible errors. The data analysis included descriptive statistics, central tendency measures, means, and the Spearman test to compare means. Data were presented in tables and charts.

The study respected the rules and guidelines for conducting research involving human beings of Resolution No. 466/2012 of the National Health Council (CNS) and obtained a favorable opinion from the ethics committee of the National Research Ethics Commission under number 4,073,466 and CAAE 31014820.4.0000.5040.

\section{RESULTS}

From 214 participants, $85.9 \%$ were female, $84.1 \%$ were between 18 and 50 years old (mean age: $36 \pm 13$ ), most were single, divorced or widowed (51.8\%), with higher education $(73.9 \%)$ and $31.31 \%$ were from the Southeast region of Brazil.

In regard to work, $44.8 \%$ started working in remotely during the pandemic while $17.7 \%$ reported continuing to work in person, which demands greater need for preventive measures against COVID-19. It is noteworthy that $31.2 \%$ stated that they were unemployed, but it was not investigated whether this situation happened during the pandemic or not.

Concerning the clinical data, type 1 diabetes predominated (76.7\%) followed by type $2(17.5 \%)$, latent autoimmune diabetes in adults (LADA) (5.6\%), and maturity-onset diabetes of the young (MODY) (0.5\%). Regarding their complications, $74.2 \%$ and $47.9 \%$ reported the absence of complications and comorbidities, respectively. Retinopathy (18.3\%) and neuropathy (16.9\%) were the most reported complications, while overweight/obesity (12.2\%), hypertension $(12.2 \%)$, and smoking $(4.7 \%)$ were the most prevalent comorbidities.

There was a high average of glycated hemoglobin (7.5 \pm 1.4) with variation between 3 and $15 \%$, with 34 people not knowing the value of the last exam/or informing the blood 
glucose value, showing that some do not know about testing, considered the gold standard and used in the assessment of glycemic control. The duration of the last exam was $4.2 \pm$ 2.2 months, ranging from one to seven months.

Participants reported self-monitoring their blood glucose 5.3 \pm 3.1 times a day, on average, indicating good adherence to this important self-care practice and $27.6 \%$ use a glucose sensor. In addition, $72.8 \%$ had already had altered glucose levels, with statistical significance for $\operatorname{sex}(p=.000)$, age $(p=$ $.026)$, education $(p=.000)$ and changes in routine (see Table 1). A total of $43.4 \%$ presented hyperglycemia and $29.4 \%$ presented hypoglycemia episodes.

Table 1. Sociodemographic and clinical characteristics of people with diabetes $(n=214)$

\begin{tabular}{lllll}
\hline & $\mathbf{n}$ & $\mathbf{\%}$ & Mean (SD) & Have you ever had altered blood glucose values? \\
\hline Gender & & & & $.000^{*}$ \\
Female & 184 & 85.9 & & \\
Male & 30 & 14.1 & & \\
Age & & & & $.026^{*}$ \\
$18-26$ & 47 & 22.0 & $36( \pm 13)$ & \\
$26-38$ & 76 & 35.5 & & \\
$38-50$ & 57 & 26.6 & & \\
$50-63$ & 23 & 10.7 & & $.000^{*}$ \\
Education level & & & \\
University education & 94 & 43.9 & & \\
Postgraduate studies & 64 & 30.0 & & \\
High school & 44 & 20.6 & & \\
Elementary School & 11 & 5.1 & & \\
Did not study & 1 & 0.4 & & \\
\hline
\end{tabular}

*Spearman test $(p<.005)$

With respect to the changes caused by the pandemic, $72 \%$ of the respondents reported changes in their diabetes self-care routine (see Table 2), such as: changes in sleep (52.8\%), physical inactivity (46.7\%), eating more frequently (39.7\%), and feeling unmotivated (38.3\%). However, some partici- pants reported positive changes, such as: improved carbohydrate count (29.4\%), being more attentive to mental health (29.4\%), and having more time available for insulin treatment and for waiting it to take effect $(24.7 \%)$. It is worth noting that some participants selected more than one option.

Table 2. Changes perceived by people with diabetes during the pandemic

\begin{tabular}{lll}
\hline What has changed in your self-care routine related with diabetes management? & $\mathbf{N}$ & $\mathbf{\%}$ \\
\hline Changes in sleep & 113 & 52.8 \\
Physical inactivity & 100 & 46.7 \\
I am eating more frequently & 85 & 39.7 \\
I start feeling unmotivated & 82 & 38.3 \\
I had improved the carbohydrate count & 63 & 29.4 \\
I am more attentive to my mental health & 63 & 29.4 \\
I started to have more time available for insulin treatment and for waiting it to take effect & 53 & 24.7 \\
I am eating less frequently & 41 & 19.1 \\
I start feeling more motivated & 29 & 13.5 \\
I am more anxious & 2 & 0.9 \\
\hline
\end{tabular}

Relating to the general preventive measures against COVID19 , the most prevalent measures among people with diabetes were wearing a mask (98.1\%), followed by washing hands Published by Sciedu Press

with soap and water (96.7\%) and using gel alcohol (94.4\%). In this item, respondents could also check more than one option (see Table 3). 
Table 3. Preventive measures against COVID-19 carried out by people with diabetes

\begin{tabular}{lll}
\hline Prevention measures & $\mathbf{N}$ & \% \\
\hline Use of mask & 210 & 98.1 \\
Handwashing with soap and water & 207 & 96.7 \\
Use of gel alcohol & 202 & 94.4 \\
Social isolation & 182 & 85.0 \\
Keep environments ventilated & 159 & 74.3 \\
Cover nose and mouth when sneezing and/or coughing & 158 & 73.8 \\
Avoid touching your hand on the face, eyes, nose, and mouth & 153 & 71.5 \\
Do not share personal items such as cutlery, glass, plates, bottles & 118 & 55.1 \\
Hand hygiene after coughing & 115 & 53.7 \\
Use of disposable fabric for nose hygiene & 40 & 18.7 \\
Use of gloves & 33 & 15.4 \\
\hline
\end{tabular}

It was observed that $91.6 \%$ were taking social distance measures because they considered it important (96.7\%) and that there was a voluntary decrease in interactions between people to minimize the transmission of the virus. In addition, all people reported using some type of mask, with cloth being the most frequent (93\%), followed by surgical mask (21.5\%) and PFF2 or N95 (12.6\%). This may be related to easier access and the cost of cloth masks when compared to other types of masks. It is noteworthy that $53(24.7 \%)$ people cited the use of more than one type of mask.

\section{Discussion}

Women with a mean age of $36 \pm 13$ years prevailed. A study on the prevalence of diabetes in the Brazilian population identified a predominance of women and individuals over 30 years, with a prevalence of 14.2 to $22.6 \%$ in people aged over 60 years. ${ }^{[14]}$

Comorbidities were reported by $52.1 \%$ of people with diabetes, increasing the risk of complications for COVID-19, as confirmed by researchers ${ }^{[12,15-17]}$ when stating that patients with at least one comorbidity, or more, have a worse clinical prognosis for COVID-19.

In Brazil, during the week of August 9 to 15, 2020, 4.3 million people were removed from work due to social distancing and 8.3 million started to work remotely, which shows the impact of the new coronavirus pandemic in several aspects of people's lives, creating insecurity and uncertainty in the face of so many changes. ${ }^{[18]}$

The glycated hemoglobin (A1c) average, a metric considered the gold standard for assessing glycemic control, ${ }^{[19]}$ found in this study was $(7.5 \pm 1.4)$, which is above the recommended target. In addition, $72.8 \%$ noticed variations in blood glucose values, with $43.4 \%$ patients having hyperglycemia episodes during the pandemic. These data are worrying and consistent with a study published in 2020 that points out that $71.2 \%$ of Brazilians with diabetes are more exposed to hyperglycemia, which makes them vulnerable to an even greater risk of poor results when infected with the SARS-CoV-2 virus. ${ }^{[4,9]}$

People with diabetes should intensify their metabolic control as a primary prevention strategy against COVID-19, since elevated A1c compromises the immune function, making people more susceptible to infectious diseases. Thus, health professionals should warn of complications, re-educate patients about the typical symptoms of hyperglycemia and ketoacidosis, and encourage them to perform regular self-monitoring of blood glucose levels every 2-4 hours or continuously. [20]

On the other hand, a positive finding was that the mean of self-monitoring of blood glucose levels ( $5.3 \pm 3.1$ times/day) was consistent with the recommendation of two or three times for patients with type 2 diabetes using less aggressive insulin regimens, and with the recommended minimum frequency of four times a day for patients with multiple insulin injections, usually before and after meals and at bedtime. ${ }^{[19]}$

A review17 pointed out preventive measures against COVID19 for people with diabetes related to water intake, healthy eating, maintenance of drug therapy, glycemic control, physical activity, smoking cessation, telehealth with a multidisciplinary team, and vaccination against other respiratory diseases. ${ }^{[10,17]}$

In addition to reinforcing metabolic control for people with diabetes as a primary prevention strategy, ${ }^{[20]}$ the review ${ }^{[17]}$ also recommends general prevention measures including using disposable or fabric masks, washing hands or using alcohol $70 \%$, adopting respiratory etiquette when coughing or sneezing, social distancing, and preserving the psychological and emotional well-being. ${ }^{[17]}$

The benefits of wearing masks during the pandemic involve 
restricting the spread of the virus and reminds to continue practicing physical distancing. Due to the shortage of surgical, N95, and PFF2 masks, facial tissue coverings are a voluntary public health strategy to contain the new coronavirus and can be made with two layers of fabric. Whatever the material of a facial mask, it must fit well and cover nose and mouth to be an effective physical barrier to prevent COVID-19. ${ }^{[21,22]}$

The use of fabric masks, the most used type in the present study, still needs further scientific proof for their effectiveness in preventing transmission. However, the use of different types of masks, and hand hygiene and other preventive measures are a relevant strategy to reduce the spread of SARS-Cov2 since the virus can be transmitted quickly by aerosols and droplets. ${ }^{[21-23]}$

The best form of prevention against the new coronavirus consists of avoiding contact with the virus through social distancing, using masks, and through the correct hygiene of hands and surfaces, ${ }^{[24]}$ consistent with the prevention measures adopted by the research participants.

Authors ${ }^{[24-26]}$ corroborate that (besides using masks) the regular washing of hands with water and soap for at least twenty seconds or thoroughly washing hands with alcohol gel (containing at least $60 \%$ alcohol) are preventive measures that must be used, especially, soon after sneezing, coughing, or visit a public place. In addition, it is necessary to avoid touching mucous membranes such as nose and mouth, and to maintain social distancing. ${ }^{[25]}$

Social distancing aims to reduce interactions between people in a community in which individuals may be infected without knowing it. ${ }^{[11]}$ Distancing, isolation, quarantine, and lockdown are public health measures whose primary purpose is to prevent the spread of the disease from person to person, keeping people away from each other and interrupting the transmission. ${ }^{[11]}$

The impact of social distancing and of the pandemic on the mental health of people with diabetes is relevant, since the prevalence of depression and anxiety among people with diabetes is high, implying difficulties in the diabetes treatment and in the glycemic control. ${ }^{[27]}$ Long-term self-isolation can have important implications for people's mental health, especially if they already experience anxiety or depression. Thus, it is essential to consider the approach of this aspect, $[10,28]$ which also influences the self-management of diabetes.

\section{Study limitations}

This study has a limitation with respect to the use of a crosssectional design, which did not allow associations over time. Another limitation is the limited reach of the questionnaire that did not include people without access to a computer and/or to the Internet. In addition, self-reported health information of diabetes may not be as accurate as compared to other sources of information and, thus, caution is needed in interpreting our findings. Nevertheless, self-reported information can be used cost-effectively in studies. It is recommended that further studies be carried out using a follow-up approach, after the pandemic, and studies analyzing other variables.

\section{Conclusions}

We could verify that people with diabetes have taken measures to prevent COVID-19, and the most prevalent were using masks, hand washing with soap and water, and using alcohol-based hand sanitizers. However, little attention was observed with care for metabolic control as a primary prevention method against COVID-19, since the participants' glycemic values were out of the recommended target.

Since people with diabetes developing COVID-19 are at increased risk for complications, the importance of developing interventions aimed at the specific needs of these patients is reinforced. These interventions include promoting the patients' adherence to the diabetes therapeutic regimen, implementing strategies to improve access of diabetic patients to healthcare (especially during lockdown situations), informing patients about the need for extra caution with respect to general precautions, and reinforcing the continuation of good dietary practices, safe physical activities, and regular glucose monitoring.

In this context of a pandemic, it is essential to continue and optimize health surveillance, cooperation, and education strategies to raise awareness of individuals to deal with their needs, ensuring self-care and better glycemic management. In addition, efforts must be maintained to respond to future new threats to public health.

\section{Conflicts OF Interest Disclosure}

The authors declare that there is no conflict of interest.

\section{REFERENCES}

[1] Correia MITD, Ramos RF, Bahten LCV. The surgeons and the COVID-19 pandemic. Rev. Col. Bras. Cir. 2020; 47: e20202536. PMid:32236295 https://doi.org/10.1590/0100-6991e-202
02536

[2] Freitas ARR, Napimoga M, Donalisio M.R. Assessing the severity of COVID-19. Epidemiol. Serv. Saúde. 2020; 29(2): e2020119. 
https://doi.org/10.5123/s1679-49742020000200008

[3] Worldometer. 2020. COVID-19 Coronavirus Pandemic [Internet]. [acesso em 2020 set 20]. Available from: https : //www . worldome ters.info/coronavirus/

[4] Barone MTU, Harnik SB, Luca PV, et al. The impact of COVID-19 on people with diabetes in Brazil. Diabetes Research and Clinical Practice. 2020; 166: 108304. PMid:32623040 https://doi.org/ 10.1016/j.diabres.2020.108304

[5] Han SB, Yang HK, Hyon JY. Influence of diabetes mellitus on anterior segment of the eye. Clinical Interventions In Aging. 2018; 14: 53-63. Informa UK Limited. PMid:30643394 https : //doi .org/ 10.2147/CIA.S190713

[6] International Diabetes Federation (Belgium). IDF diabetes atlas. 2019.

[7] Cavalcante JR, Cardoso-dos-Santos AC, Bremm JM, et al. COVID-19 in Brazil: evolution of the epidemic up until epidemiological week 20 of 2020. Epidemiol. Serv. Saúde [Internet]. 2020; 29(4): e2020376. https://doi.org/10.5123/S1679-49742020000400010

[8] Kulcsar KA, Coleman CM, Beck SE, et al. Comorbid diabetes results in immune dysregulation and enhanced disease severity following MERS-CoV infection. Jci Insight. 2019; 4(20): 1-19. PMid:31550243 https://doi.org/10.1172/jci.insight.13 1774

[9] Silva ALDA, Matias LDM, Freitas JMS, et al. COVID-19 prevention measures in people living with diabetes mellitus. Revista Enfermagem Atual In Derme. Edição especial covid19 - 2020; e-020004.

[10] Wu Z, McGoogan J. Characteristics of and Important Lessons from the Coronavirus Disease 2019 (COVID-19) Outbreak in China. JAMA Network. 2020; 323(13): 1239-42. PMid:32091533 https : //doi.org/10.1001/jama.2020.2648

[11] Wilder-Smith A, Freedman DO. Isolation, quarantine, social distancing and community containment: pivotal role for old-style public health measures in the novel coronavirus (2019-nCoV) outbreak. J Travel Med. 2020; 27(2). PMid:32052841 https ://doi.org/10 .1093/jtm/taaa020

[12] Kratzel A, Todt D, V'kovski P, et al. Efficient inactivation of SARSCoV-2 by WHO recommended hand rub formulations and alcohols. BioRxiv. 2020.

[13] Costa BRL. Bola de Neve Virtual: O Uso das Redes Sociais Virtuais no Processo de Coleta de Dados de uma Pesquisa Científica. Revista Interdisciplinar de Gestão Social. 2018; 7(1): 15-37.

[14] Malta DC, et al. Prevalence of diabetes mellitus as determined by glycated hemoglobin in the Brazilian adult population, National Health Survey. Rev Bras Epidemiol. 2019; 22(suppl 2): E190006.

[15] Guan WJ, Ni ZY, Hu Y, et al. Clinical characteristics of coronavirus disease 2019 in China. New England journal of Medicine. 2020;
382(18): 1708-20. PMid:32109013 https ://doi.org/10.1056/ NEJMoa2002032

[16] Jordan RE, Adab P, Cheng KK. Covid-19: risk factors for severe disease and death. BMJ. 2020; 368 : m1198 DOI: $10.1136 / \mathrm{bmj}$. m1198. Available from: https://www.bmj.com/content/bmj/368/bmj.m1198.full.pdf PMid:32217618 https : //doi.org/10.1136/bmj .m1198

[17] Wu Z, McGoogan J. Characteristics of and Important Lessons From the Coronavirus Disease 2019 (COVID-19) Outbreak in China. JAMA Network. 2020; 323(13): 1239-42. PMid:32091533 https : //doi.org/10.1001/jama.2020.2648

[18] Ibge. PNAD-covid-19. O IBGE apoiando o combate à COVID-19. Indicadores de saúde. https://covid19.ibge.gov.br/pnad-c ovid/

[19] Brazilian Diabetes Society. Guidelines of the Brazilian Diabetes Society 2019-2020. São Paulo: Clannad, 2019.

[20] Bornstein SR, Rubino F, Khunti K, et al. Practical recommendations for the management of diabetes in patients with COVID-19. Lancet Diabetes Endocrinol. 2020; 8: 546-50. https://doi.org/10.101 6/S2213-8587(20)30152-2

[21] Desai AN, Aronoff DM. Masks and Coronavirus Disease 2019 (COVID-19). JAMA. 2020; 323(20): 2103. PMid:32301960 https : //doi.org/10.1001/jama.2020.6437

[22] Anvisa. Agência Nacional de Vigilância Sanitária. Orientações Gerais - Máscaras faciais de uso não profissional. [Internet]. 2020. Available from: http://portal.anvisa.gov.br/documents /219201/4340788/NT+M\%C3\%A1scaras .pdf/bf430184-855 0-42cb-a975-1d5e1c5a10f 7

[23] Ma QX, Shan H, Zhang HL, et al. Potential utilities of mask-wearing and instant hand hygiene for fighting SARS-CoV-2. J Med Virol. [Preprint]. 2020 Mar [cited Apr 23, 2020]; 1-5. PMid:32232986 https://doi.org/10.1002/jmv. 25805

[24] Pimentel, et al. Trends and limitations of antiseptic solutions in hygienization and prevention to the new coronavirus. Journal of Biology \& Pharmacy and Agricultural Management. 2020; 16(4).

[25] Hafeez A, Ahmad S, Siddqui SA, et al. A Review of COVID-19 (Coronavirus Disease-2019): Diagnosis, Treatments and Prevention. Eurasian Journal of Medicine and Oncology. 2019; 4(2): 116-25.

[26] Lotfinejad N, Peters A, Pittet D. Hand hygiene and the novel coronavirus pandemic: The role of healthcare workers. Journal of Hospital Infection. 2020; 105(4): 776-7. PMid:32201339 https : //doi.org/10.1016/j.jhin.2020.03.017

[27] Santos EJ, Santos VC. Depression among people with diabetes mellitus. Rev. Saúde. Com. 2019; 15(1): 1421-1431. https ://doi.or g/10.22481/rsc.v15i1.4222

[28] Down S. COVID-19 and diabetes. Journal of Diabetes Nursing 24: JDN121. 2020. 